\title{
The Arabidopsis P450 protein CYP82C2 modulates jasmonate- induced root growth inhibition, defense gene expression and indole glucosinolate biosynthesis
}

Fang Liu ${ }^{1}$, Hongling Jiang ${ }^{1}$, Songqing Ye ${ }^{2}$, Wen-Ping $\mathrm{Chen}^{2}$, Wenxing Liang ${ }^{1}$, Yingxiu $\mathrm{Xu}^{1}$, Bo Sun ${ }^{3}$, Jiaqiang Sun ${ }^{1}$, Qiaomei Wang ${ }^{3}$, Jerry D Cohen ${ }^{2}$, Chuanyou $\mathrm{Li}^{1}$

${ }^{I}$ State Key Laboratory of Plant Genomics, National Centre for Plant Gene Research, Institute of Genetics and Developmental Biology, Chinese Academy of Sciences, No.1 West Beichen Road, Chaoyang District, Beijing 100101, China; ${ }^{2}$ Department of Horticultural Science and Microbial and Plant Genomics Institute, University of Minnesota, Saint Paul, MN 55108, USA, ${ }^{3}$ Department of Horticulture, Zhejiang University, Hangzhou 310029, China

Jasmonic acid (JA) is a fatty acid-derived signaling molecule that regulates a broad range of plant defense responses against herbivores and some microbial pathogens. Molecular genetic studies have established that JA also performs a critical role in several aspects of plant development. Here, we describe the characterization of the Arabidopsis mutant jasmonic acid-hypersensitive1-1 (jah1-1), which is defective in several aspects of JA responses. Although the mutant exhibits increased sensitivity to JA in root growth inhibition, it shows decreased expression of JA-inducible defense genes and reduced resistance to the necrotrophic fungus Botrytis cinerea. Gene cloning studies indicate that these defects are caused by a mutation in the cytochrome $\mathbf{P 4 5 0}$ protein CYP82C2. We provide evidence showing that the compromised resistance of the jah1-1 mutant to $B$. cinerea is accompanied by decreased expression of JA-induced defense genes and reduced accumulation of JA-induced indole glucosinolates (IGs). Conversely, the enhanced resistance to $B$. cinerea in CYP82C2-overexpressing plants is accompanied by increased expression of JA-induced defense genes and elevated levels of JA-induced IGs. We demonstrate that CYP82C2 affects JA-induced accumulation of the IG biosynthetic precursor tryptophan (Trp), but not the JA-induced IAA or pathogen-induced camalexin. Together, our results support a hypothesis that CYP82C2 may act in the metabolism of Trp-derived secondary metabolites under conditions in which JA levels are elevated. The jah1-1 mutant should thus be important in future studies toward understanding the mechanisms underlying the complexity of JA-mediated differential responses, which are important for plants to adapt their growth to the ever-changing environments.

Keywords: jasmonic acid, root growth inhibition, defense response, indole glucosinolates, tryptophan

Cell Research (2010) 20:539-552. doi:10.1038/cr.2010.36; published online 30 March 2010

\section{Introduction}

The jasmonate family of oxylipins, including jasmonic acid (JA), methyl JA (MeJA) and other bioactive derivatives (collectively referred to here as JAs) are important signaling molecules in the plant kingdom. JAs have a well-established role in regulating defense responses

Correspondence: Chuanyou Li

Tel: +86-10-64865313; Fax: +86-10-64873428

E-mail: cyli@genetics.ac.cn

Received 14 October 2009; revised 15 December 2009; accepted 26 January 2010, published online 30 March 2010 against herbivore attack and pathogen infection. In addition to defense, JAs also regulate many aspects of plant growth and development [1-5].

It has long been recognized that the application of exogenous JAs inhibits root growth [6], and this action has been employed as the most prominent genetic screen to identify mutants with defective JA responses in the reference species, Arabidopsis thaliana $[2,4,7]$. Mutantbased molecular genetic studies have identified several important components of JA signaling. The coronatine insensitivel (coil) mutant is fully insensitive to JA in both root growth inhibition and defense gene expression [8]. COII encodes an F-box protein showing active E3 
ligase activity $[9,10]$. Very recently, COI1 was identified as a JA receptor [11]. Compared with coil, the jasmonate-resistant1 (jar1) [7] and jasmonate-insensitive1 (jin1) $[12,13]$ mutants exhibit relatively weak phenotypes in the JA-induced inhibition of root growth. JAR1 encodes an enzyme that has JA adenylation activity to form JA-amino acid conjugates, especially JA-isoleucine (JA-Ile), demonstrating that JA-Ile is the primary jasmonate signal [14-16]. JIN1 encodes a nuclear-localized basic helix-loop-helix-type transcription factor known as AtMYC2 [13], which acts as both an activator and a repressor to regulate diverse aspects of JA-mediated gene expression [17]. A family of Arabidopsis proteins named JAZ (jasmonate ZIM domain) was identified as targets of the $\mathrm{SCF}^{\mathrm{COI} 1}$ ubiquitin ligase complex in JA signaling [18, 19]. The JAZ family proteins represent a molecular link between $\mathrm{SCF}^{\mathrm{COI1}}$-mediated protein degradation and transcriptional activation of JA responses [18].

An intact JA signaling pathway is required for plant resistance against the infection of necrotrophic pathogens, such as B. cinerea and Erwinia carotovora [20]. It was believed that the regulatory role of JA in plant resistance to pathogen infections is possibly achieved through activating the expression of a number of defense-related genes, including genes encoding proteins with antimicrobial properties. Both JA treatment and pathogen infection induce the expression of the plant defensin gene PDF1.2 $[21,22]$ and the basic thionin gene Thi2.1 [23]. Arabidopsis mutants defective in JA production or signaling are blocked in pathogen-induced expression of PDF 1.2 and Thi2.1 and are more susceptible to different fungal pathogens [24, 25]. Conversely, an Arabidopsis mutant with increased endogenous JA levels showed constitutive expression of Thi2.1 and PDF1.2 and enhanced resistance to powdery mildew infections [26].

Accumulating evidence has indicated that JA also influences the production of various defense-related metabolites, including glucosinolates, which are nitrogenand sulfur-containing secondary metabolites with a wide range of biological functions [27-29]. On tissue damage, glucosinolates are hydrolyzed by a thioglucosidase called myrosinase to form a series of biologically active compounds such as isothiocyanates, thiocyanates and nitriles [30-32]. Many of these products have been implicated as being important for plant defenses against pathogens and herbivores. Several studies with different plant species indicated that JA induces the production of tryptophan (Trp)-derived indole glucosinolates (IGs), but not aromatic and aliphatic glucosinolates [27, 33-36]. It was generally believed that the JA-induced accumulation of IGs is regulated at the transcriptional level. However, the regulatory interactions between defense signaling and IG metabolism remain largely unknown.

Here, we describe the characterization of the Arabidopsis jasmonic acid-hypersensitive1-1 (jah1-1) mutant that shows altered responses to JA in root growth inhibition and defense gene expression. We show that CYP82C2 encodes a predicted cytochrome P450 protein. The results that we report support the hypothesis that CYP82C2 acts to alter the metabolism of Trp-derived secondary metabolites under conditions in which JA levels are elevated.

\section{Results}

The jah1-1 mutant is hypersensitive to JA in root growth inhibition

A T-DNA-mutagenized population of Arabidopsis [37] was screened for plants showing altered responses to relatively low concentrations of JA using the widely applied root growth inhibition assay. A mutant line was identified because it developed short roots on medium containing $10 \mu \mathrm{M}$ JA (Figure 1A). In the absence of JA, primary root length of the mutant seedlings was comparable to that of wild-type plants. However, in the presence of a range of concentrations of JA, roots of the mutant plants were generally shorter than those of wild-type plants (Figure 1A and 1B). For example, under our growth conditions, roots of 8-day-old wild-type seedlings were $30.6 \pm 2.6 \mathrm{~mm}$ in length, and reduced by $45 \%$ to $16.9 \pm$ $0.9 \mathrm{~mm}$ when grown on medium containing $10 \mu \mathrm{M} \mathrm{JA}$. In contrast, roots of the mutant seedlings were $29.8 \pm 2.8$ $\mathrm{mm}$ in length and were reduced by $70 \%$ to a length of 9.0 $\pm 1.9 \mathrm{~mm}$ when grown on medium containing $10 \mu \mathrm{M} \mathrm{JA}$. These results indicate that the mutant line is more sensitive than wild type to the inhibitory effect of exogenous JA on root growth. The specificity of jah1-1 in the JA signaling pathway was addressed by testing the sensitivity of jahl-1 to several other hormones including ABA, ethylene and auxin, and also to abiotic stress reagents including $\mathrm{NaCl}$ and mannitol. As shown in Supplementary information, Figure S1, no significant differences in seedling development were observed in these assays between jah1-1 and wild type, suggesting that the jah1-1 mutant defines a specific regulator of JA response.

\section{jah1-1 is defective in JA-induced gene expression}

Increased sensitivity of jah1-1 to JA-mediated inhibition of root growth prompted us to investigate whether JA-induced defense gene expression was affected in this mutant. In Arabidopsis, JA is believed to regulate the expression of two distinct sets of defense-related genes by different mechanisms $[13,38]$. One group of these genes, including the plant defensin gene PDF1.2 [21] 
and the thionin gene Thi2.1 [39], is associated with plant defense to pathogen infections. The other group, including VEGETATIVE STORAGE PROTEIN1 (VSP1) [40] and LIPOXYGENASE2 (LOX2) genes [41], is believed to be associated with wound responses. The levels of JA-in-

A

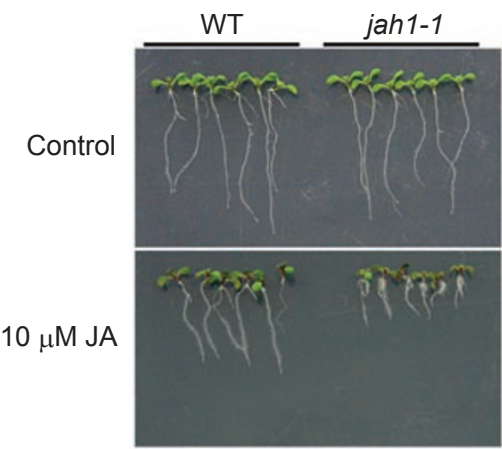

B
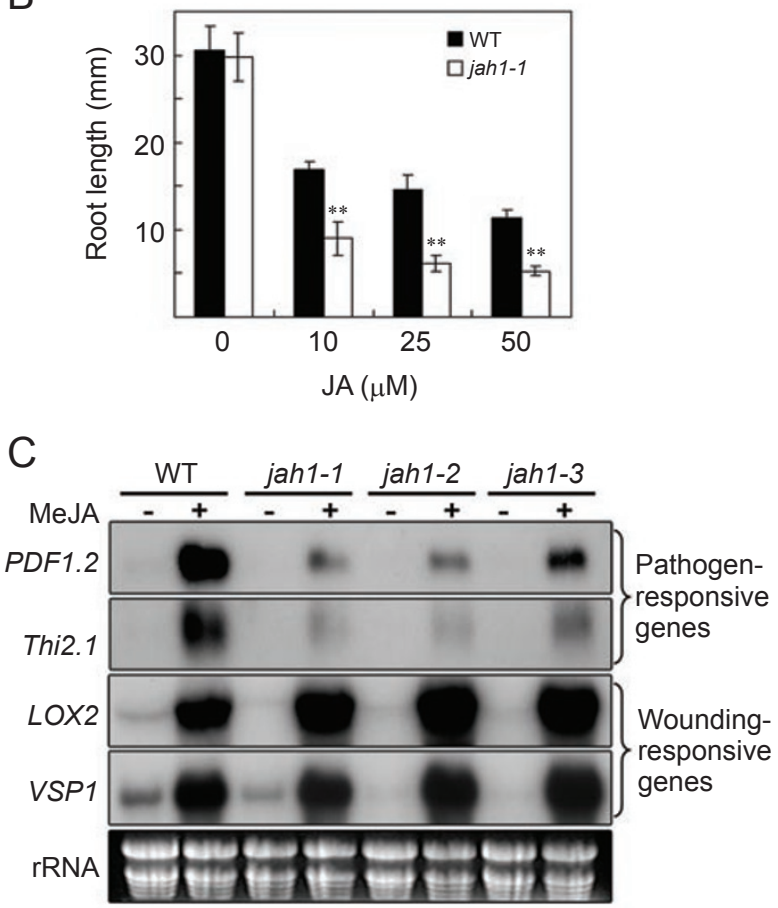

Figure 1 Phenotypes of jah1 mutants. (A) Root growth of 8-dayold wild-type (WT) and jah1-1 seedlings grown in the absence (Control) or presence of $10 \mu \mathrm{M} \mathrm{JA}$. (B) Root length of 8-dayold WT and jah1-1 seedlings grown on medium containing indicated concentrations of JA. Data show the mean \pm SD of three independent experiments. Asterisks denote Student's $t$ test significance compared with wild type $(* * P<0.01)$. (C) RNA gel blot analysis of JA-inducible genes (PDF1.2, Thi2.1, LOX2 and VSP1) in the indicated genotypes. Seedlings (2 weeks old) were treated with water (-) or $50 \mu \mathrm{M} \mathrm{MeJA} \mathrm{(+)} \mathrm{for} 6 \mathrm{~h}$ and tissues were collected for RNA extraction. Total RNA $(20 \mu \mathrm{g})$ was loaded per lane, and blots were hybridized with the indicated probes. rRNA serves as a loading control.

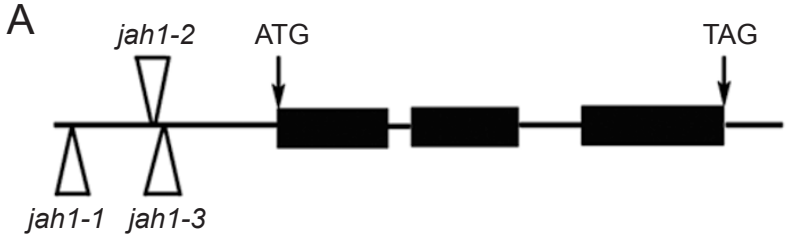

B

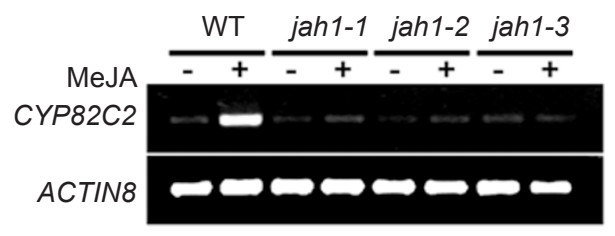

Figure 2 Identification of the CYP82C2 gene. (A) A diagram of the CYP82C2 gene structure. Black boxes indicate the coding sequence, open boxes indicate the 5'- and 3'-untranslated regions, and lines between boxes indicate introns. Positions of the T-DNA insertions in different alleles of the jah1 mutant are indicated. (B) CYP82C2 expression in different alleles of the jah1 mutant analyzed by RT-PCR. Seedlings ( 2 weeks old) were treated with water $(-)$ or $50 \mu \mathrm{M}$ MeJA $(+)$ for $48 \mathrm{~h}$ and tissues were collected for RNA extraction. Amplification of the ACTIN8 gene served as a control.

duced expression of PDF1.2 and Thi2.1 genes were substantially reduced in jahl-1 (Figure 1C). In contrast, JAinduced expression of the wound-responsive $L O X 2$ and VSP1 genes was largely unaffected (Figure 1C). These results indicate that the jahl-1 mutation mainly affects JAinduced expression of pathogen defense-related genes.

The JA-response phenotype of jah1-1 results from a defect in CYP82C2

Genetic analysis indicated that jahl-1 defines a single recessive mutation in a nuclear gene. The T-DNA-inserted genomic region was isolated by thermal asymmetric interlaced-PCR (TAIL-PCR), and sequence analysis revealed that the T-DNA was inserted at $900 \mathrm{bp}$ upstream of the translation start codon of the CYP82C2 gene (At4g31970), which encodes cytochrome P450 monooxygenase (Figure 2A). As shown in the RT-PCR assays, the T-DNA insertion in jah1-1 led to significant reduction of CYP82C2 expression (Figure 2B).

A $4.0 \mathrm{~kb}$ genomic DNA fragment containing the entire CYP $82 C 2$ coding region and a $1.5 \mathrm{~kb}$ upstream sequence was introduced into the jahl-1 background. The results showed that the CYP82C2 genomic DNA complemented the jah1-1 mutant in JA-mediated root growth inhibition, defense gene expression and defense response against $B$. cinerea infection (Supplementary information, Figure S2).

Further confirmation that CYP82C2 was responsible for the jah 1-1 mutant phenotype came from analy- 
ses of two independent T-DNA insertion lines named SALK_128974 and SALK_024364. As shown in Figure 2A, SALK_128974 and SALK_024364 contain T-DNAs inserted at $627 \mathrm{bp}$ and $537 \mathrm{bp}$, respectively, upstream of the translation start codon of CYP $82 C 2$. These T-DNA insertions significantly reduced the expression levels of CYP82C2 (Figure 2B). Similar to jah1-1 plants, homozygous SALK_128974 and SALK_024364 plants showed a JA-hypersensitive phenotype in root growth inhibition

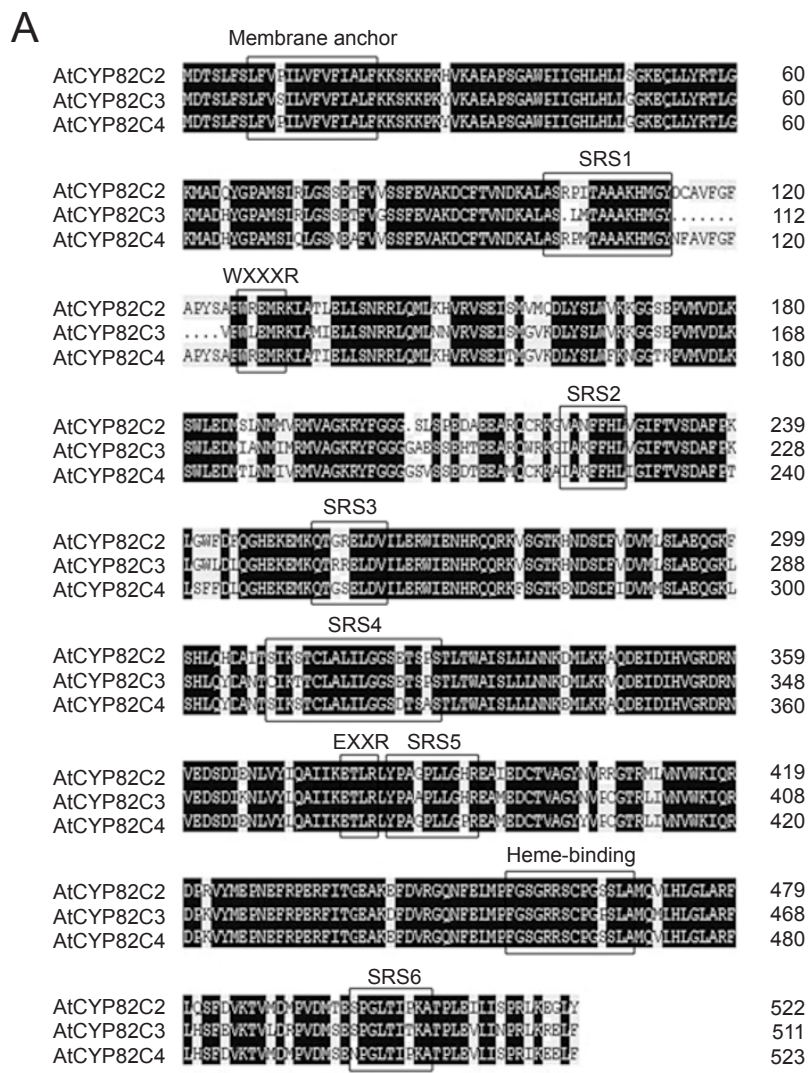

\section{B}

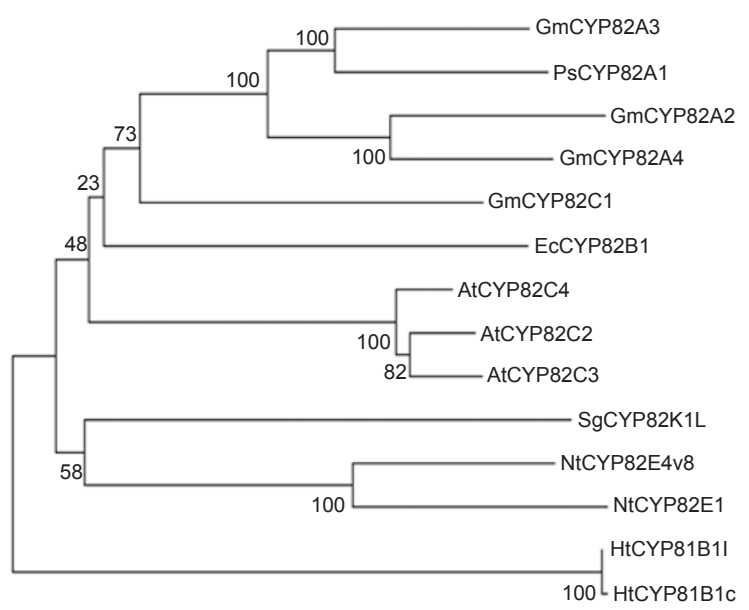

(Supplementary information, Figure S3) and they were therefore designated as jahl-2 and jahl-3, respectively. As expected, JA-induced expression levels of PDF 1.2 and Thi2.1 genes were also significantly reduced in jah12 and jah1-3 (Figure 1C). Genetic analyses showed that jah1-1, jah1-2 and jah1-3 cannot complement each other, indicating that these mutations are allelic (Supplementary information, Figure S3). Collectively, these results showed that CYP82C2 was responsible for the jah1-1 mutant phenotype.

CYP82C2 contains three exons and encodes a putative protein of 524 amino acids (Figure 2A). Sequence analysis revealed that CYP82C2 contains all the highly conserved domains, characteristic for the eukaryotic P450 proteins [42]: the N-terminal proline-rich domain involved in membrane anchoring, the WXXXR domain, the substrate recognition site (SRS) regions, the EXXR region and the heme-binding domain (Figure 3A). In the Arabidopsis genome, CYP82C2 is a member of a cluster of three $C Y P 82 C$ genes, comprising CYP82C2, CYP82C3 (At4g31950) and CYP82C4 (At4g31940). The deduced amino acid sequence of CYP82C2 was almost similar to CYP82C4 (89\% identity) and CYP82C3 (88\% identity, Figure 3B). Notably, the most significant difference among the three CYP82C members was that CYP82C3 contained a deletion of 11 amino acids, which occurs immediately after SRS1 region and preceding WXXXR domain (Figure 3A). Considering that the deletion removed a large portion of the C-helix, which is potentially important for substrate binding [42], CYP82C3 may show altered biochemical activity compared to CYP82C2 or CYP82C4. However, little information is available concerning the biochemical function of the CYP82C subfamily.

Figure 3 CYP82C2 encodes the cytochrome P450 CYP82C2. (A) Sequence alignment of CYP82C2 with CYP82C3 and CYP82C4. Sequence alignment was done by DNAMAN4.0 (Lynnon Biosoft). Black backgrounds are identical residues; gray backgrounds are similar ones; dotted lines indicate gaps. Framed regions indicate locations of conserved domains of microsomal P450s, including the membrane anchor region, the WXXXR domain, the substrate recognition site (SRS) regions, the EXXR region and the heme-binding domain. (B) Phylogenetic analysis of CYP82C2 and the selected stress-inducible P450 proteins from Glycine $\max (\mathrm{Gm})$, Pisum sativum (Ps), Eschscholzia californica (Ec), Arabidopsis thaliana (At), Stylosanthes guianensis $(\mathrm{Sg})$ and Nicotiana tabacum $(\mathrm{Nt})$ plants. A neighbor-joining tree construction was performed by the MEGA4 program (http://www.megasoftware.net/). Topological robustness was assessed by bootstrap analysis with 500 replicates. The scale bar is an indicator of genetic distance based on branch length. 
A
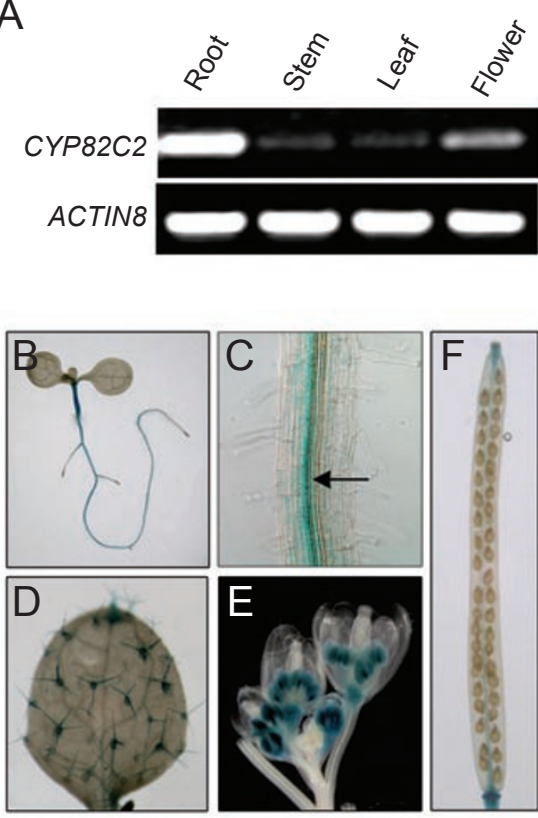

G

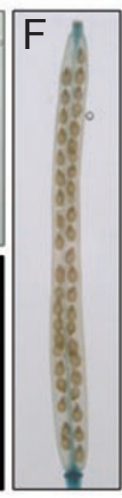

$\mathrm{H}$
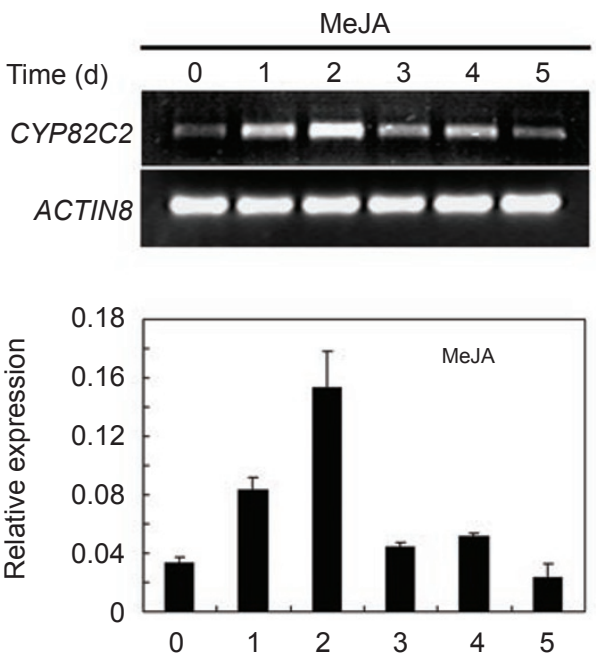

(d)

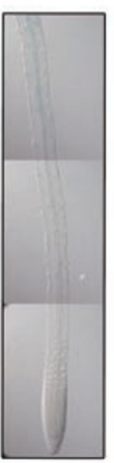

Control

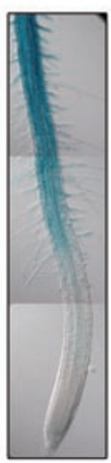

MeJA
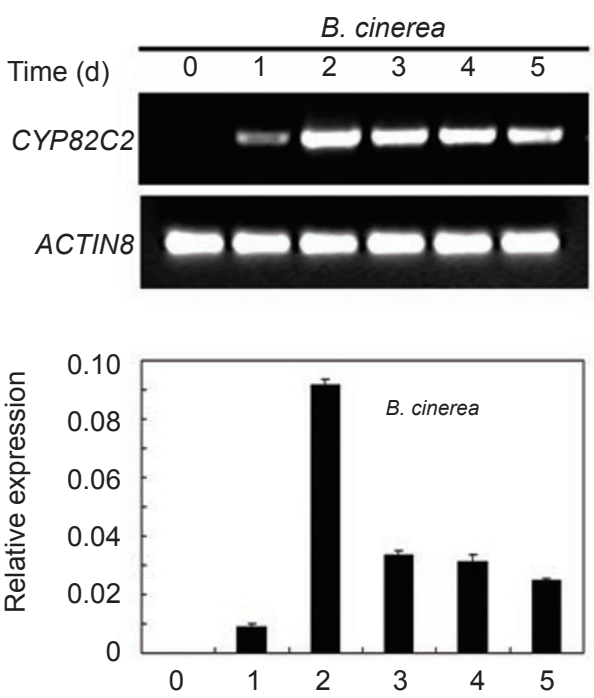

(d)

Figure 4 Temporal and spatial patterns of CYP82C2 expression. (A) RT-PCR analysis of CYP82C2 expression in different tissues. Total RNA was isolated from roots, stems, leaves and flowers of wild-type (WT) plants. Amplification of the ACTIN8 gene serves as a control. (B) CYP82C2:GUS expression in 6-day-old seedling. (C) CYP82C2:GUS expression in root vascular tissues of 6-day-old seedling. (D) CYP82C2:GUS expression in leaf of 14-day-old seedling. (E) CYP82C2:GUS is richly expressed in anthers of open flowers. (F) CYP82C2:GUS expression in silique. (G) MeJA-induced CYP82C2:GUS expression in the root. CYP82C2:GUS seedlings (4 days old) were exposed to $50 \mu \mathrm{M}$ MeJA or water (Control) for 2 days and stained overnight. (H) MeJA-induced CYP82C2 expression analyzed by RT-PCR (top) and qRT-PCR (bottom) assays. WT plants (2 weeks old) were treated with $50 \mu \mathrm{M}$ MeJA for the indicated time periods. (I) B. cinerea-induced CYP82C2 expression analyzed by RT-PCR (top) and qRT-PCR (bottom) assays. WT (4 weeks old) plants grown in the soil were inoculated with a $5-\mu \mathrm{l}$ droplet of $B$. cinerea spore suspension at a density of $10^{5}$ spores per $\mathrm{ml}$ for the indicated time periods. (H and $\left.\mathbf{I}\right)$ The transcript levels of CYP82C2 are normalized based on the expression of ACTIN8. Data are mean \pm SD of three independent experiments.

CYP82C2 expression is upregulated by MeJA treatment and $B$. cinerea infection

The expression pattern of CYP82C2 was determined by RT-PCR analysis. CYP82C2 was shown to be expressed in all examined tissue types including roots, stems, leaves and flowers (Figure 4A). The highest ex- pression level of CYP82C2 was found in roots, followed by flowers, with relatively low expression in stems and leaves. A DNA fragment covering the $1.5 \mathrm{~kb}$ promoter region of CYP $82 C 2$ was fused with the glucuronidase (GUS) reporter gene and transformed into wildtype plants. Representative transgenic plants named 
CYP82C2:GUS were used to follow the promoter activity of $C Y P 82 C 2$ at different developmental stages. In 6-day-old seedlings, GUS activity was detected predominantly in roots and hypocotyls, and weakly in cotyledons (Figure 4B). Closer observation of 6-day-old seedlings revealed that GUS staining in roots was mainly focused in the vascular tissues (Figure 4C). In leaves of 14-dayold plants, GUS activity was detected in trichomes (Figure 4D). In flowers, GUS activity was mainly observed in the anthers (Figure 4E). In nearly mature siliques, GUS was barely detectable in seeds, but richly expressed in the pedicel-silique junctions (Figure 4F).

To examine whether the expression of CYP82C2 was JA inducible, the CYP82C2:GUS transgenic plants were treated with MeJA and the GUS activity was monitored. CYP82C2:GUS expression in the root was significantly increased following MeJA treatment (Figure 4G). To study the induction kinetics of MeJA on CYP82C2 expression, 2-week-old wild-type seedlings were treated with MeJA and the accumulation of CYP82C2 transcripts was measured with RT-PCR and quantitative RT-PCR (qRT-PCR) assays at different times. The CYP82C2 transcripts started to increase at 1 day after MeJA treatment and reached a maximum at 2 days (Figure 4H). The transcript level started to drop after 3 days. A similar induction pattern of CYP82C2 expression was observed when 4-week-old soil-grown plants were infected with the necrotrophic pathogen $B$. cinerea (Figure 4I). These results suggest that CYP82C2 possibly plays a role in MeJAmediated defense responses against pathogen infection.

The MeJA-induced expression of CYP82C2 is independent of COII

To study whether the JA-induced expression of CYP82C2 requires the function of COI1, a central regulator of jasmonate-mediated processes in Arabidopsis [9], we compared the MeJA-induced CYP82C2 expression in the wild type and the coil-1 mutant plants [9]. Interestingly, qRT-PCR analysis showed that the coil-1 mutation did not significantly affect the expression of CYP82C2 in the absence or presence of MeJA (Figure 5A), indicating that MeJA induced the expression of CYP82C2 in a COI1-independent manner. We also generated a double mutant between jah1-1 and coil-2, which is insensitive to JA, but partially fertile and able to produce a small quantity of seeds [43]. The jah1-1/coil-2 double mutant was compared with jah1-1, coil-2 and wild type for JAinduced root growth inhibition. In the absence of JA, 8 -day-old seedlings of the four genotypes showed comparable root length. In the presence of JA, however, the root length of the double mutant showed high similarity to that of the coil-2 mutant, i.e., insensitive to JA-
A

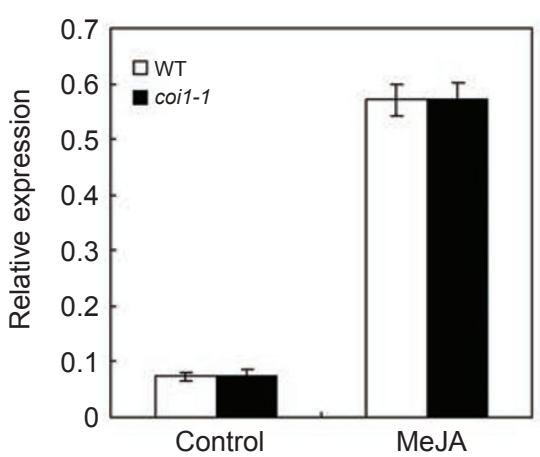

B
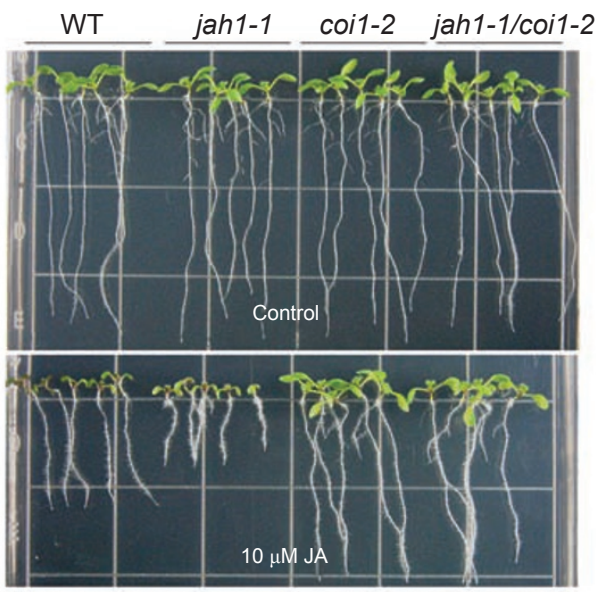

C

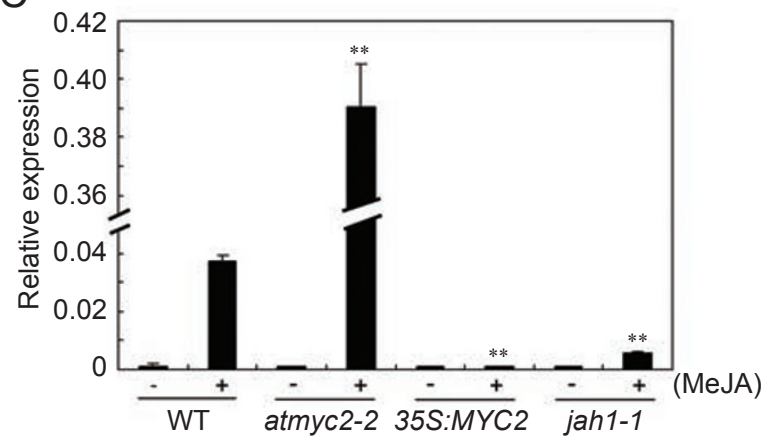

Figure 5 MeJA-induced expression of CYP82C2 in coi1-1 and atmyc2-2. (A) qRT-PCR analysis of MeJA-induced CYP82C2 expression in wild type (WT) and coi1-1. Seedlings (2 weeks old) were treated without (Control) or with $50 \mu \mathrm{M}$ MeJA for 48 h. The transcript levels of the CYP82C2 were normalized to the ACTIN8 expression. Data are mean \pm SD of three independent experiments. Student's $t$-test was performed and did not detect a significant difference compared with WT plants $(P>0.05)$. (B) WT (8 days old), jah1-1, coi1-2 and jah1-1/coi1-2 (from left to right) seedlings grown on medium without (Control) or with $10 \mu \mathrm{M}$ JA. (C) qRT-PCR analysis of MeJA-induced CYP82C2 expression in WT, atmyc2-2, 35S:MYC2 and jah1-1. Seedlings (2 weeks old) were treated with water (-) or $50 \mu \mathrm{M}$ MeJA (+) for $48 \mathrm{~h}$. The transcript levels of CYP82C2 were normalized based on the expression of ACTIN8. Data are mean \pm SD of three independent experiments. Asterisks denote Student's $t$-test significance compared with wild type $(* * P<0.01)$. 
mediated inhibition, which was in contrast to the JAhypersensitive phenotype of jahl-1 (Figure 5B). This observation further indicated that the root growth phenotype of jahl-1 was specific to JA.

We also tested whether the MeJA-induced expression of the CYP82C2 gene was regulated by AtMYC2, an important regulator of a wide range of JA-mediated gene expression $[13,17,38]$. As shown in Figure 5C, the MeJA-induced expression levels of CYP82C2 were considerably increased in the atmyc2-2 mutant that disrupts AtMYC2 expression, while decreased in 35S:MYC2, an

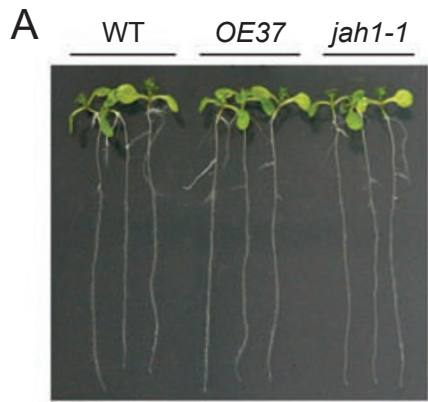

Control

B

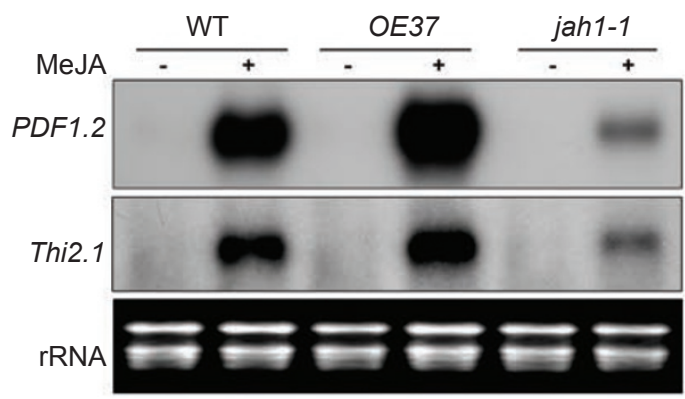

C

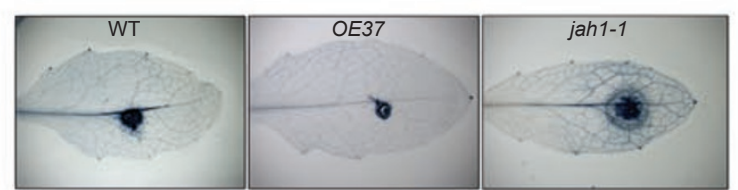

D

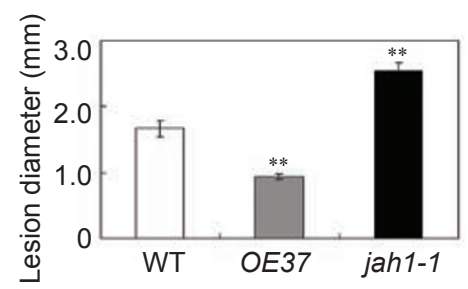

$E$

B. cinerea infection
AtMYC2-overexpressor [38]. These results indicate that the JA-induced expression of CYP82C2 is negatively regulated by AtMYC2.

CYP82C2 plays an important role in plant resistance to $B$. cinerea infection

To investigate the physiological role of $C Y P 82 C 2$ further, we generated transgenic Arabidopsis plants overexpressing the CYP82C2 cDNA driven by the cauliflower mosaic virus $35 \mathrm{~S}$ promoter. Overexpression of $C Y P 82 C 2$ in transgenic lines was confirmed by RNA gel blot analysis (data not shown). All the CYP82C2 overexpression lines showed similar JA-related phenotypes; thus, only the results obtained with one representative line, named OE37, are discussed below.

Under normal growth conditions, the overall growth rate and morphology of $O E 37$ plants were similar to those of wild-type and jahl-1 plants (Figure 6A). However, in the presence of JA, roots of $O E 37$ were longer than those of wild type (Figure 6A), suggesting that, in contrast to jah1-1, OE37 is less sensitive to JA-mediated inhibition of root growth. We next compared the expression levels of JA-induced PDF1.2 and Thi2.1 genes among the three genotypes using RNA gel blot analysis. In response to MeJA treatment, a significantly elevated level of these mRNAs was observed in OE37 plants (Figure 6B). In contrast, jah1-1 plants showed decreased expression levels of MeJA-induced PDF1.2 and Thi2.1 genes (Figure 6B), which is consistent with the results described earlier (Figure 1C).

$O E 37$ and jah1-1 were then compared with wildtype plants for their response to pathogen infection.

Figure 6 CYP82C2 plays an important role in plant resistance against $B$. cinerea infection. (A) 35S:CYP82C2 (OE37) plants are less sensitive to JA in root growth inhibition. Shown are 8-day-old seedlings of the indicated genotypes grown on medium without (Control) or with $10 \mu \mathrm{M} \mathrm{JA}$. (B) 35S:CYP82C2 (OE37) plants show increased MeJA-induced defense gene expression. Seedlings ( 2 weeks old) of the indicated genotypes were treated with water (-) or $50 \mu \mathrm{M}$ MeJA (+) for $6 \mathrm{~h}$ and MeJA-induced expression of PDF1.2 and Thi2.1 was analyzed by RNA gel blot tissues. (C) Hyphae growth revealed by lactophenol-trypan blue staining. Representative leaves of the indicated genotypes are shown. (D) Lesion size generated by $B$. cinerea was measured 5 days after inoculation. Data are mean \pm SD of three independent experiments. Asterisks denote Student's $t$-test significance compared with wild type (**P<0.01). (E) RNA gel blot analysis of PDF1.2 expression in the indicated genotypes after $B$. cinerea infection. (B and E) Total RNA $(20 \mu \mathrm{g})$ was loaded per lane and rRNA serves as a loading control. (C-E), 4-week-old plants were inoculated with spore suspensions of $B$. cinerea as described in Experimental procedures, disease symptoms were investigated 5 days after inoculation. 
Soil-grown plants (4 weeks old) were challenged with $B$. cinerea and the infection progress was monitored. At 5 days after inoculation, while wild-type plants produced restricted necrotic lesions, jah1-1 plants produced spreading lesions that were heavily colonized by the fungal hyphae (Figure 6C). The average diameter of the necrotic lesions of $B$. cinerea-infected jahl-1 plants was significantly larger than that of the infected wildtype plants (Figure 6D). These results indicate that jahl1 plants are more susceptible to $B$. cinerea than wildtype plants. In contrast, $O E 37$ plants showed an apparent reduction in infection symptoms compared with wildtype plants, when assessed by trypan blue staining of the infected leaves and by measuring the size of the necrotic lesions (Figure 6C and 6D), indicating that $O E 37$ plants were more resistant to $B$. cinerea. Consistent with the performance of the three genotypes on pathogen infection, the jah1-1 plants infected by $B$. cinerea showed significantly reduced expression levels of $P D F 1.2$, whereas OE37 plants showed increased expression levels of this gene (Figure 6E). Together, these data demonstrate that CYP82C2 is important for plant resistance to B. cinerea, and that overexpression of $C Y P 82 C 2$ was sufficient to increase plant resistance to this pathogen.

\section{CYP82C2 affects MeJA-induced Trp accumulation}

The CYP82 family of P450 proteins is only present in Arabidopsis and other dicot plants, but is absent in the rice genome [44]. Members of the CYP82 family (Figure 3B) are reported to be highly stress responsive in
A

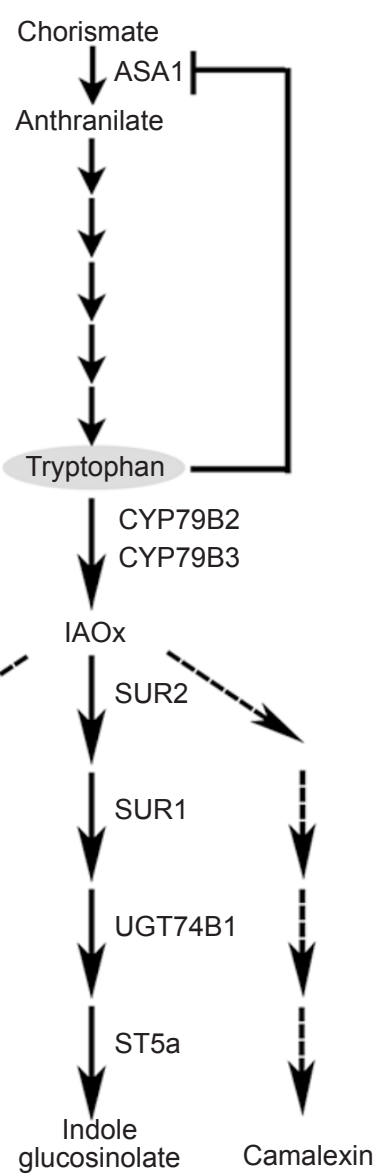

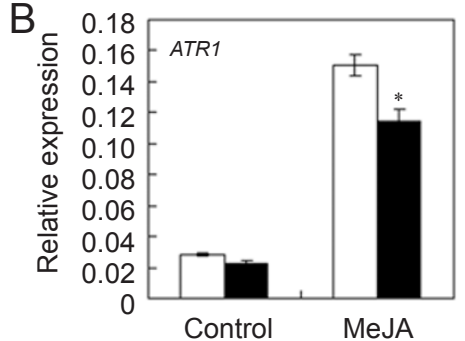
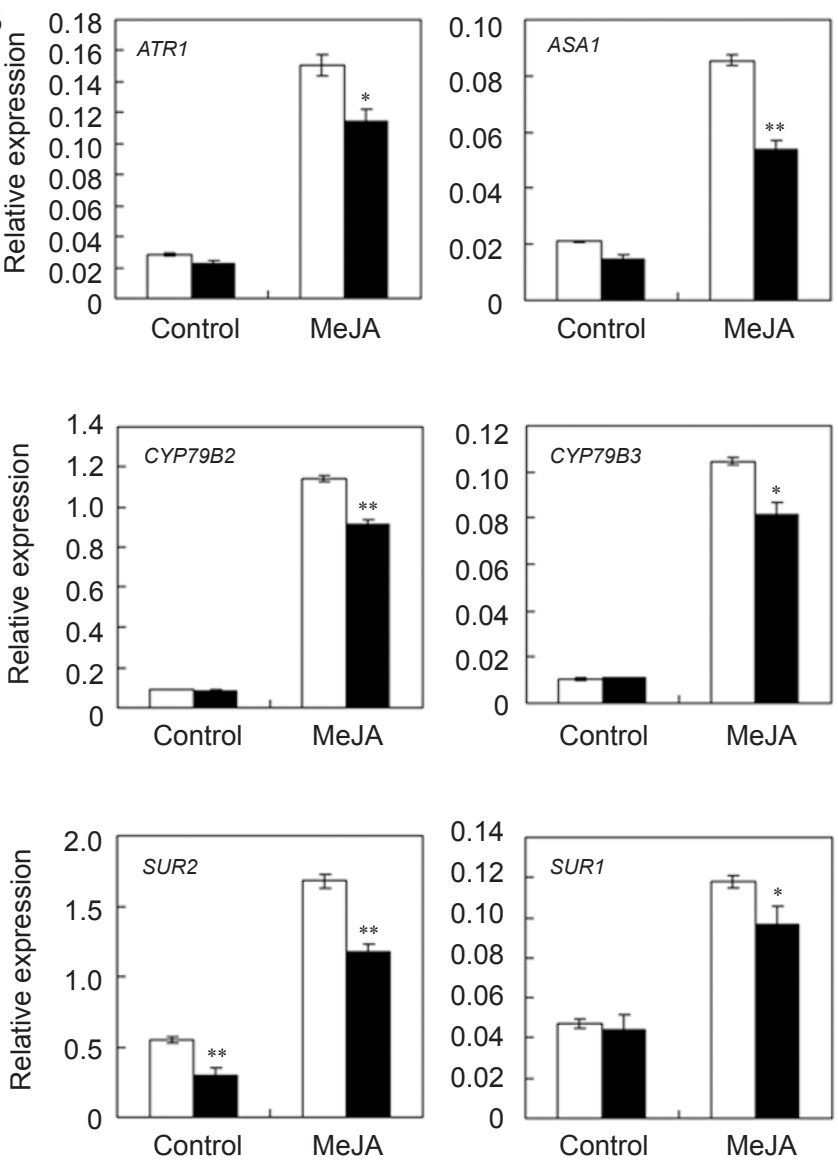

Figure 7 MeJA-induced expression of Trp-pathway genes in wild type and jah1-1. (A) Trp metabolism in Arabidopsis. The pathway for Trp biosynthesis and its subsequent conversion into IGs, IAA or camalexin via IAOx is shown, with key enzymatic steps discussed in the text. Trp feedback inhibition of AS activity is indicated by a line with a perpendicular bar at ASA1. The dashed arrow indicates that the number of biosynthetic steps in the IAA and camalexin pathways is unknown. (B) qRT-PCR analyses of MeJA-regulated expression of ATR1, ASA1, CYP79B2, CYP79B3, SUR2 and SUR1 in WT and jah1-1. Seedlings (2 weeks old) were treated without (Control) or with $50 \mu \mathrm{M}$ MeJA for $6 \mathrm{~h}$. The transcript levels of the indicated genes were normalized to the ACTIN8 expression. Data are mean \pm SD of three independent experiments. Asterisks denote Student's $t$-test significance between wild type (white bar) and jah1-1 (black bar) $(* P<0.05, * * P<0.01)$. 
pea (Pisum sativum), tobacco (Nicotiana tabacum) and soybean (Glycine max) [45-48]. These, together with our finding that the $C Y P 82 C 2$ gene plays a role in plant resistance to $B$. cinerea, led us to a hypothesis that $C Y P 82 C 2$ may be involved in the production of species-specific secondary metabolites that are important for disease resistance. Arabidopsis plants derive a number of important secondary metabolites from the amino acid Trp, including the growth regulator IAA and defense compounds such as IGs and camalexin (Figure 7A). To test whether CYP82C2 may affect the Trp pathway, we compared MeJA-induced expression levels of several genes involved in Trp synthesis or metabolism between wildtype and jahl-1 plants. As shown in Figure 7B, the MeJA-induced expression levels of the Trp synthesis gene $A S A 1$, which encodes the $\alpha$-subunit of anthranilate synthase (AS, Figure 7A) [49], were significantly reduced in jah1-1 compared to the levels in the wild type (Figure 7B). Similarly, the MeJA-induced expression levels of the Trp-metabolizing genes CYP79B2 and CYP79B3 (Figure 7A) [50], were also significantly reduced in jahl1 as compared with wild type (Figure 7B).

Next, we measured Trp accumulation in wild type, jah1-1 and the CYP82C2-overexpressor OE37. In the absence of MeJA, Trp levels were similar among the three genotypes (Figure 8A). As expected, MeJA treatment led to significant increase of Trp accumulation in wild type, and the MeJA-mediated induction of Trp levels was impaired by the jah1-1 mutation (Figure 8A). Surprisingly, however, the MeJA-mediated induction of Trp levels was more severely impaired in $O E 37$ than shown in the jah1-1 mutant (Figure 8A), suggesting an increased Trpmetabolizing flux in the CYP82C2 overexpressor.

CYP82C2 affects MeJA-induced biosynthesis of IGs, but not of IAA and camalexin

In Arabidopsis, CYP79B2 and CYP79B3 specifically catalyze the conversion of Trp to IAOx (indole-3-acetaldoxime), which is then directed into the biosynthesis of IGs, camalexin or IAA (Figure 7A) [51, 52]. Our finding that CYP82C2 affects JA-induced Trp accumulation prompted us to determine whether CYP82C2 played a role in the biosynthesis of IGs, camalexin or IAA. Interestingly, we found that the MeJA-induced expression levels of several IG biosynthesis-related genes including ATR1 [53], SUPERROOT2 (SUR2) [54, 55] and SUPERROOT1 (SUR1) [56] were reduced in the jah1-1 mutant, as compared with wild type (Figure 7B), suggesting that CYP82C2 may affect MeJA-induced biosynthesis of IGs. To test this, we treated 14-day-old plants with MeJA and measured the levels of three major IGs including indol-3-ylmethyl glucosinolate, 4-methoxy-indol-3-
A

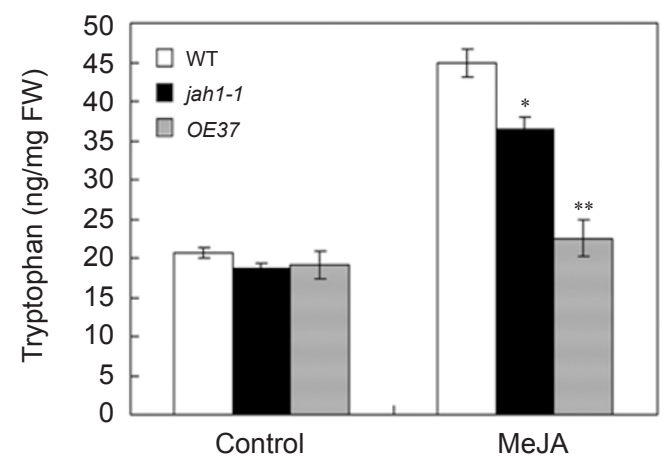

B

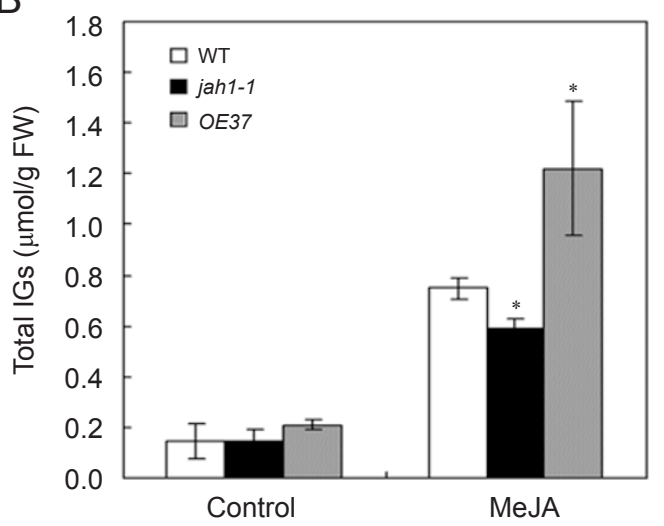

C

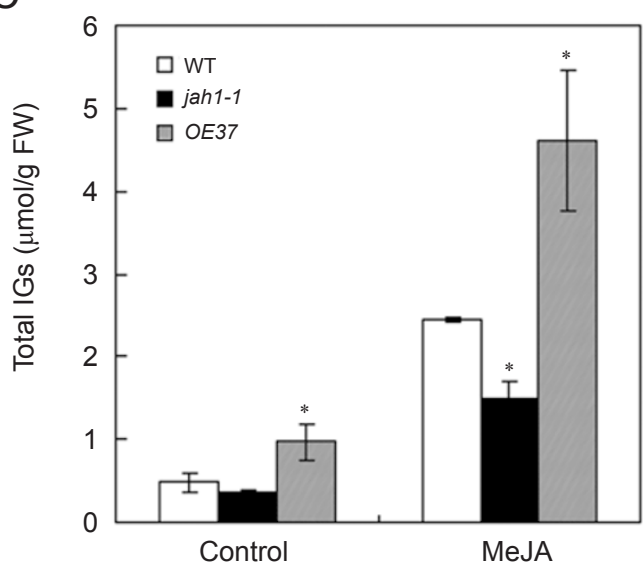

Figure 8 CYP82C2 affects MeJA-induced accumulation of Trp and IGs. (A) CYP82C2 affects MeJA-induced accumulation of Trp levels. Seedlings (10 days old) of the indicated genotypes were treated without (Control) or with $100 \mu \mathrm{M}$ MeJA for 2 days and then Trp levels were measured by GC-MS. Values indicate mean \pm SEM of three biological replicates. Asterisks indicate the significant difference from the wild type (two-way ANOVA, $* P<$ $0.05, * * P<0.01)$. (B and C) CYP82C2 affects MeJA-induced biosynthesis of IGs. Seedlings (2 weeks old) of the indicated genotypes were treated with water (Control) or $50 \mu \mathrm{M}$ MeJA for 2 days, and total IGs were extracted from leaves (B) and roots (C) and measured by HPLC. Values indicate mean \pm SD of three biological replicates. Asterisks denote Student's $t$-test significance compared with wild type $(* P<0.05)$. 
ylmethyl glucosinolate and 1-methoxy-indol-3-ylmethyl glucosinolate (Supplementary information, Figure S4). Figure $8 \mathrm{~B}$ shows the calculation of the results of the total IGs in leaves. In the absence of MeJA, the basal levels of total IGs were similar among jah1-1, OE37 and wildtype plants. In line with previous findings, MeJA treatment led to significant increase of IG levels in all the three genotypes. However, while the levels of total IGs in jah1-1 were lower than those in wild type, OE37 plants accumulated significantly higher levels of total IGs than wild-type plants (Figure 8B).

Considering the fact that the jahl mutants are hypersensitive to JA-mediated inhibition of root growth and that $C Y P 82 C 2$ is preferentially expressed in the root, we further measured the levels of IGs extracted from roots of the same set of plants, as shown in Figure 8B. In the absence of MeJA, roots of OE37 plants contained significantly higher levels of total IGs than wild-type and jah1-1 plants (Figure 8C). In response to MeJA treatment, total IGs in jah1-1 roots were significantly lower than those in wild type, whereas total IGs in OE37 were significantly higher than those in wild type (Figure 8C). These results indicate that $C Y P 82 C 2$ affects MeJAinduced biosynthesis of IGs.

Given the potential of a tight link between the biosynthesis of IGs and IAA from the common intermediate IAOx, we measured MeJA-induced free IAA levels in wild type, jah1-1 and OE37 plants. Without MeJA treatment, free IAA levels were similar among the three genotypes (Supplementary information, Figure S5). MeJA treatment increased free IAA levels in all of the three genotypes and, again, the MeJA-induced free IAA levels did not exhibit significant difference among wild type, jah1-1 and OE37 plants (Supplementary information, Figure S5), indicating that CYP82C2 does not affect MeJA-induced IAA biosynthesis.

We also measured camalexin production following infection with Alternaria brassicicola and found that both jah1-1 and OE37 show wild type levels of camalexin accumulation (Supplementary information, Figure S6). In contrast, the pad3 (phytoalexin-deficient 3) mutant [57] produced a smaller amount of camalexin in response to the same pathogen.

\section{Discussion}

CYP82C2 differentially modulates JA-induced root growth inhibition and defense gene expression

The inhibitory effect of JA on primary root growth has been widely employed as a genetic assay to identify JA-related mutants in Arabidopsis. Most of the JAinsensitive mutants, including jarl [7, 24], jin1 and jin4
[12] were identified by screening for JA-insensitive root growth in the presence of relatively high concentrations of JA or MeJA (50 to $100 \mu \mathrm{M}$ ). To identify additional components involved in JA signaling, we set up a genetic screen by using relatively low doses of JA $(10 \mu \mathrm{M}$ in this study). The mutant jahl-1 was identified because it showed stunted root growth in response to low concentrations of JA. Given that the root growth of jahl1 was normal in control medium and showed increased sensitivity to the inhibitory effect of JA (Figure 1A and 1B), this mutant was considered to be hypersensitive to JA-mediated inhibition of root growth. In contrast to root growth inhibition, however, jah1-1 was less sensitive to JA in induction of defense gene expression, because the JA-induced expression levels of defense-related genes, including PDF1.2 and Thi2.1, were decreased in this mutant (Figure 1C). The known JA-related mutants, including cev1 [26] and cexl [58], exhibit stunted root growth without JA and constitutively express JA-induced defense genes. Therefore, the differential regulation of JA-induced root growth inhibition and defense gene expression in jahl-1 identifies this mutant as being distinct from the known JA-related mutants. It is noteworthy that the jah1-1 mutation mainly affected JA-induced expression of pathogen defense-related genes, but had little effect on the JA-induced expression of wound-responsive genes including LOX2 and VSP1 (Figure 1C). Together, these observations support a hypothesis that JA-induced root growth inhibition and defense response are regulated by different mechanisms. In line with previous findings that not all of the JA responses were mediated through the F-box protein COI1 [59-62], which was recently shown to be a jasmonate receptor [11, 15, 18, 19], we found that MeJA induced the expression of CYP82C2 in a COI1-independent manner. COI1-independent expression of CYP82C2 is consistent with its effect on JA-induced IG biosynthesis. It has been demonstrated that the JA-induced production of IGs does not rely completely on COI1, as coil-1 plants produce IGs, albeit at lower levels $[27,35,63]$. Together, our characterization of the jahl mutant revealed the complexity of JA-mediated responses. Future elucidation of the biochemical function of the CYP82C2 protein should provide evidence to help explain the versatile aspects of the jahl mutant phenotype.

\section{CYP82C2 is important for plant resistance to B. cinerea}

From the publicly available microarray database, we noticed that the expression of CYP82C2 was induced by pathogen infections [64]. Our gene expression analyses indicated that while the jahl-1 plants were defective in JA-induced expression of a group of pathogen defense 
genes including PDF1.2 and Thi2.1 (Figure 1C), transgenic plants overexpressing $C Y P 82 C 2$ showed increased expression of these genes (Figure 6B). Given that the expression of $P D F 1.2$ and Thi2.1 is associated with plant resistance to pathogens [24-26], together with the fact that the expression of CYP82C2 itself was induced by both JA treatment and pathogen inoculation (Figure 4G4I), our results suggest that $C Y P 82 C 2$ may play a role in plant resistance to pathogen infection. Indeed, pathogen attack assays indicated that while the jah1-1 mutant plants were more susceptible to the necrotrophic fungus $B$. cinerea, transgenic plants overexpressing $C Y P 82 C 2$ were more resistant (Figure 6C and 6D). On the basis of these findings, we conclude that the CYP82C2 gene plays an important role in plant defense responses against the necrotrophic fungus $B$. cinerea.

\section{CYP82C2 affects MeJA-induced synthesis of Trp and IGs}

Metabolic profiling of the Trp-pathway compounds revealed that the expression level of CYP82C2 affects MeJA-induced accumulation of Trp (Figure 8A), which is then converted into IAOx. As a key metabolic branch point, IAOx can be directed to the biosynthesis of IGs, camalexin or IAA, in a highly regulated manner (Figure 7A) [51]. Our data revealed an effect of CYP82C2 on the MeJA-induced biosynthesis of IGs, as evidenced by the reduction of IG levels in the jah1-1 mutant and the increase of IG levels in CYP82C2-overexpressing plants (Figure $8 \mathrm{~B}$ and $8 \mathrm{C}$ ). The effect of CYP82C2 on IG metabolism was further supported by analysis of its expression pattern (Figure 4B-4E). CYP82C2 was expressed in all examined tissues, with the highest level being found in roots. The expression pattern of CYP82C2 was consistent with the known fact that IGs are most prominent in the root and with the root growth phenotype of jahl1 seedlings in JA-containing medium. Furthermore, the expression of CYP $82 C 2$ was induced by MeJA treatment and $B$. cinerea infection, which was consistent with previous reports that IG biosynthesis can be induced by JAs in several Brassica species [27, 33, 34]. However, a direct biochemical function of the CYP82C2 protein in IG biosynthesis remains to be determined.

It has been proposed that IAOx, the direct Trp-metabolizing product by the CYP79B2 and CYP79B3 genes, plays a central role in the biosynthesis of IGs, camalexin or IAA (Figure 7A). It has been shown that postoxime blockage of the IG biosynthetic pathway leads to increased IAA biosynthesis. For example, the sur1 [65], sur2 [54] and ugt74B1 [66] mutants gained their highauxin phenotype by blocking post aldoxime enzymes in the glucosinolate pathway. On the other hand, mutational blockage of enzymes acting upstream of IAOx leads to a low-auxin phenotype. For example, the cyp79B2 cyp $79 B 3$ double mutant produced less IGs and decreased levels of IAA in a temperature-dependent manner [50]. In this context, determination of whether free IAA levels were altered in jah1-1 was important in order to understand the possible site of action of the CYP82C2 gene in the metabolic pathways leading to indolic compounds. However, we did not find any significant difference in free IAA levels among wild-type, jah1-1 or OE37 seedlings with or without of MeJA treatment (Supplementary information, Figure S5). We also measured camalexin levels in response to $A$. brassicicola infection and did not find significant difference among the three genotypes (Supplementary information, Figure S6). Taken together, our metabolic profiling of the Trp-pathway compounds indicate that CYP82C2 affects the MeJA-induced production of Trp and IGs, but not the MeJA-induced production of IAA and pathogen-induced camalexin. We propose that CYP82C2 might act in a step involved in converting Trp to IGs under conditions in which JA levels are increased. This hypothesis is consistent with our finding that the MeJA-induced production of Trp was significantly reduced in the CYP82C2 overexpressing line, in which the Trp-metabolizing flux is increased. Future experiments that include measuring JA-induced IAOx should enable us to define CYP82C2 activity as being downstream or upstream of IAOx. Under this scenario, the reduction of MeJA-induced Trp production in the jah1-1 could be explained by Trp feedback control mechanisms. Trp biosynthesis in Escherichia coli is found to be regulated by three distinct negative feedback control mechanisms, namely, transcriptional repression, transcriptional attenuation and feedback enzyme inhibition [67]. In Arabidopsis, it has been well documented that Trp may inhibit the activity of AS through feedback mechanism by binding to an allosteric site on the catalytic $\alpha$-subunit of AS $[68,69]$. In this way, although the blockage in the Trpmetabolizing pathway may lead to increased Trp content in jah 1-1, this increase in Trp accumulation might induce a feedback inhibition of AS activity and, eventually, lead to a reduced Trp production. However, relatively little is known about the transcript regulation of AS from plants. We found that the MeJA-induced expression of ASA1, which encodes the $\alpha$-subunit of AS [69], was downregulated in jahl-1 (Figure 7B), suggesting that AS may also be regulated at the transcriptional level in Arabidopsis.

\section{Materials and Methods}

\section{Biological materials and growth conditions}

All A. thaliana lines used were in the Columbia (Col-0) background. The jahl-2 (SALK_128974) and jahl-3 (SALK_024364) 
mutants were obtained from the Arabidopsis Biological Resources Center. A homozygous T-DNA insertion line (SALK 083483, designated as atmyc2-2), which disrupted the expression of AtMYC2, was described previously [38]. The coil-1 [8], coil-2 [11] and pad3 [57] mutants were previously described. Arabidopsis plants were grown as described [70]. Growth and spore harvesting of the fungus $B$. cinerea and A. brassicicola was done as described [71].

\section{Isolation of the jah1-1 mutant}

Seeds of a T-DNA mutagenized population of Arabidopsis [37] were germinated on a medium containing $10 \mu \mathrm{M}$ JA (Sigma). Plates were placed vertically in a growth chamber for 8 to 10 days and seedlings with shorter roots were selected as putative jah mutants. Seeds from the putative mutants were retested on MS medium with $10 \mu \mathrm{M}$ JA by measuring root elongation. The jahl-1 was one of the identified mutants showing elevated responses to JA in root growth. Further characterization of the mutant was performed with a homozygous line obtained from three successive backcrosses of the original mutant with the wild-type parental plant Col-0.

\section{Cloning of the CYP82C2 gene}

The $C Y P 82 C 2$ gene was identified with TAIL-PCR assay [72]. Three T-DNA-specific primers (LexA2, LexA4 and LexA5) and an arbitrary degenerate primer (AD3) were used for the primary, secondary and tertiary reactions, respectively. To determine the location of the T-DNA insertions, the amplified fragments from the tertiary PCR were sequenced using LexA5 as a primer. Homozygous T-DNA insertion lines for jah1-1, jah1-2, jah1-3 and atmyc2-2 were identified with diagnostic PCR using gene-specific primers and T-DNA primers (Supplementary information, Table S1). Homozygous coil/coil plants were selected from the progeny of coil/COI1 heterozygous plants as described (Supplementary information, Table S1) [9].

For complementation analysis, a $4.0 \mathrm{~kb}$ DNA fragment containing the entire CYP82C2/At4g31970 coding region and the $1.5 \mathrm{~kb}$ upstream sequence was amplified from wild-type plant (Col-0) by PCR and cloned into the $K p n \mathrm{I} / X b a \mathrm{I}$ sites of pCAMBIA1300 to generate the jahl-comp. construct. A $1.5 \mathrm{~kb}$ promoter for CYP82C2 was PCR amplified and cloned into the HindIII/BamHI sites of pCAMBIA1391Z to generate the CYP82C2:GUS construct. The coding sequences of CYP82C2 cDNA was amplified by PCR and cloned into the $\mathrm{BamHI} / \mathrm{SacI}$ sites of pCanG-HA under the control of the $35 \mathrm{~S}$ promoter to generate the $35 \mathrm{~S}: \mathrm{CYP} 82 \mathrm{C} 2$ construct. Similarly, we also generated a 35S:MYC2 construct. Primers used for PCR amplification are listed in Supplementary information, Table S1. The above constructs were then electroporated into Agrobacterium tumefaciens strain GV3101 as described [73], which were used for transformation of Arabidopsis plants by vacuum infiltration.

\section{Gene expression assays}

Total RNA was prepared by a guanidine thiocyanate extraction method. RNA gel blot, RT-PCR and qRT-PCR analyses were performed as described previously [70]. Gene-specific primers are listed in Supplementary information, Table S1.

Histochemical staining for GUS activity in transgenic plants was performed as described [74].

\section{Induction treatments}

Plants (2 weeks old) growing in Petri dishes were sprayed with $50 \mu \mathrm{M}$ MeJA (Sigma), and the controls were sprayed with water. Soil-grown plants (4 weeks old) were sprayed with $1 \times 10^{5}$ B.cinerea spores per $\mathrm{ml}$. Tissues were then harvested at indicated time intervals for RNA extraction.

\section{Fungal disease assay}

Plants (4 weeks old) were infected with a 5- $\mu$ ldrop of $B$. $c i$ nerea $\left(1 \times 10^{5}\right.$ spores per $\left.\mathrm{ml}\right)$ or with buffer as the control and covered with clear plastic to maintain high humidity. At least 15 plants per genotype were inoculated in each experiment. Infection and development of the fungus were visualized by lactophenol-trypan blue staining as described [75].

\section{Measurement of Trp, IAA and camalexin levels}

Measurement of Trp, IAA and camalexin levels was described in Supplementary information, Data S1.

\section{HPLC analysis of glucosinolates}

Seedlings ( 2 weeks old) were treated with $50 \mu \mathrm{M}$ MeJA solution for 2 days and IGs were extracted from leaves or roots. Analysis of IGs by HPLC was performed as previously described [76].

\section{Acknowledgments}

We gratefully acknowledge Dr Jianru Zuo (Institute of Genetics and Developmental Biology, Chinese Academy of Sciences, China) for providing T-DNA mutagenized population of Arabidopsis, Dr Salomé Prat (Institut de Biologia Molecular de Barcelona, Spain) for providing homozygous atmyc2-2 mutant (T-DNA insertion line SALK_083483) seeds and Dr Jane Glazebrook for assisting with camalexin measurements. This work was supported by grants from the Chinese Academy of Sciences (KSCX2YW-N-045, KSCX2-YW-N-015), the Ministry of Agriculture of China (2008ZX08009-003-001) and the Ministry of Science and Technology of China (2007CB948201, 2006AA10A116). Work in the laboratory of Jerry D Cohen was supported by grants from the US National Science Foundation (MCB-0725149 and DBIPGRP-0606666) and the USDA, National Research Initiative (2005-35318-16197).

\section{References}

1 Creelman RA, Mullet JE. Biosynthesis and action of jasmonates in plants. Annu Rev Plant Physiol Plant Mol Biol 1997; 48:355-381.

2 Turner JG, Ellis C, Devoto A. The jasmonate signal pathway. Plant Cell 2002; 14:S153-S164.

3 Browse J. Jasmonate: an oxylipin signal with many roles in plants. Vitam Horm 2005; 72:431-456.

4 Wasternack C. Jasmonates: an update on biosynthesis, signal transduction and action in plant stress response, growth and development. Ann Bot 2007; 100:681-697.

5 Howe GA, Jander G. Plant immunity to insect herbivores. Annu Rev Plant Biol 2008; 59:41-66.

6 Ueda J, Kato J. Isolation and identification of a senescencepromoting substance from wormwood (Artemisia absinthium L.). Plant Physiol 1980; 66:246-249.

7 Staswick PE, Su WP, Howell SH. Methyl jasmonate inhibition of root-growth and induction of a leaf protein are decreased in an Arabidopsis thaliana mutant. Proc Natl Acad Sci USA 
1992; 89:6837-6840.

8 Feys BJF, Benedetti CE, Penfold CN, Turner JG. Arabidopsis mutants selected for resistance to the phytotoxin coronatine are male-sterile, insensitive to methyl jasmonate, and resistant to a bacterial pathogen. Plant Cell 1994; 6:751-759.

9 Xie DX, Feys BF, James S, Nieto-Rostro M, Turner JG. COI1: an Arabidopsis gene required for jasmonate-regulated defense and fertility. Science 1998; 280:1091-1094.

10 Devoto A, Nieto-Rostro M, Xie D, et al. COI1 links jasmonate signaling and fertility to the SCF ubiquitin-ligase complex in Arabidopsis. Plant J 2002; 32:457-466.

11 Yan J, Zhang C, Gu M, et al. The Arabidopsis CORONATINE INSENSITIVE1 protein is a jasmonate receptor. Plant Cell 2009; 21:2220-2236.

12 Berger S, Bell E, Mullet JE. Two methyl jasmonate-insensitive mutants show altered expression of AtVsp in response to methyl jasmonate and wounding. Plant Physiol 1996; 111:525-531.

13 Lorenzo O, Chico JM, Sanchez-Serrano JJ, Solano R. JASMONATE-INSENSIVE1 encodes a MYC transcription factor essential to discriminate between different jasmonateregulated defense responses in Arabidopsis. Plant Cell 2004; 16:1938-1950.

14 Staswick PE, Tiryaki I. The oxylipin signal jasmonic acid is activated by an enzyme that conjugates it to isoleucine in Arabidopsis. Plant Cell 2004; 16:2117-2127.

15 Katsir L, Schilmiller AL, Staswick PE, He SY, Howe GA. COI1 is a critical component of a receptor for jasmonate and the bacterial virulence factor coronatine. Proc Natl Acad Sci USA 2008; 105:7100-7105.

16 Fonseca S, Chini A, Hamberg M, et al. (+)-7-iso-JasmonoylL-isoleucine is the endogenous bioactive jasmonate. Nat Chem Biol 2009; 5:344-350.

17 Dombrecht B, Xue GP, Sprague SJ, et al. MYC2 differentially modulates diverse jasmonate-dependent functions in Arabidopsis. Plant Cell 2007; 19:2225-2245.

18 Chini A, Fonseca S, Fernandez G, et al. The JAZ family of repressors is the missing link in jasmonate signaling. Nature 2007; 448:666-671.

19 Thines B, Katsir L, Melotto M, et al. JAZ repressor proteins are targets of the $\mathrm{SCF}^{\mathrm{COI} 1}$ complex during jasmonate signaling. Nature 2007; 448:661-665.

20 Glazebrook J. Contrasting mechanisms of defense against biotrophic and necrotrophic pathogens. Annu Rev Phytopathol 2005; 43:205-227.

21 Penninckx IAMA, Eggermont K, Terras FRG, et al. Pathogen-induced systemic activation of a plant defensin gene in Arabidopsis follows a salicylic acid-independent pathway. Plant Cell 1996; 8:2309-2323.

22 Penninckx IAMA, Thomma BPHJ, Buchala A, Metraux JP, Broekaert WF. Concomitant activation of jasmonate and ethylene response pathways is required for induction of a plant defensin gene in Arabidopsis. Plant Cell 1998; 10:2103-2113.

23 Epple P, Apel K, Bohlmann H. An Arabidopsis thaliana thionin gene is inducible via a signal transduction pathway different from that for pathogenesis-related proteins. Plant Physiol 1995; 109:813-820.

24 Staswick PE, Yuen GY, Lehman CC. Jasmonate signaling mutants of Arabidopsis are susceptible to the soil fungus $P y$ thium irregulare. Plant J 1998; 15:747-754.
25 Thomma BPHJ, Eggermont K, Tierens KFMJ, Broekaert WF. Requirement of functional ethylene-insensitive 2 gene for efficient resistance of Arabidopsis to infection by Botrytis cinerea. Plant Physiol 1999; 121:1093-1102.

26 Ellis C, Turner JG. The Arabidopsis mutant cev1 has constitutively active jasmonate and ethylene signal pathways and enhanced resistance to pathogens. Plant Cell 2001; 13:10251033.

27 Mikkelsen MD, Petersen BL, Glawischnig E, Jensen AB, Andreasson E, Halkier BA. Modulation of CYP79 genes and glucosinolate profiles in Arabidopsis by defense signaling pathways. Plant Physiol 2003; 131:298-308.

28 Bednarek P, Pislewska-Bednarek M, Svatos A, et al. A glucosinolate metabolism pathway in living plant cells mediates broad-spectrum antifungal defense. Science 2009; 323:101106.

29 Clay NK, Adio AM, Denoux C, Jander G, Ausubel FM. Glucosinolate metabolites required for an Arabidopsis innate immune response. Science 2009; 323:95-101.

30 Wittstock U, Halkier BA. Glucosinolate research in the Arabidopsis era. Trends Plant Sci 2002; 7:263-270.

31 Grubb CD, Abel S. Glucosinolate metabolism and its control. Trends Plant Sci 2006; 11:89-100.

32 Halkier BA, Gershenzon J. Biology and biochemistry of glucosinolates. Annu Rev Plant Biol 2006; 57:303-333.

33 Bodnaryk RP. Potent effect of jasmonates on indole glucosinolates in oilseed rape and mustard. Phytochemistry 1994; 35:301-305.

34 Doughty KJ, Kiddle GA, Pye BJ, Wallsgrove RM, Pickett JA. Selective induction of glucosinolates in oilseed rape leaves by methyl jasmonate. Phytochemistry 1995; 38:347-350.

35 Brader G, Tas E, Palva ET. Jasmonate-dependent induction of indole glucosinolates in Arabidopsis by culture filtrates of the nonspecific pathogen Erwinia carotovora. Plant Physiol 2001; 126:849-860.

36 Sasaki-Sekimoto Y, Taki N, Obayashi T, et al. Coordinated activation of metabolic pathways for antioxidants and defence compounds by jasmonates and their roles in stress tolerance in Arabidopsis. Plant J 2005; 44:653-668.

37 Zhang J, Xu JX, Kong YZ, et al. Generation of chemicalinducible activation tagging T-DNA insertion lines of Arabidopsis thaliana. Acta Genet Sin 2005; 32:1082-1088.

38 Boter M, Ruiz-Rivero O, Abdeen A, Prat S. Conserved MYC transcription factors play a key role in jasmonate signaling both in tomato and Arabidopsis. Genes Dev 2004; 18:15771591.

39 Vignutelli A, Wasternack C, Apel K, Bohlmann H. Systemic and local induction of an Arabidopsis thionin gene by wounding and pathogens. Plant J 1998; 14:285-295.

40 Berger S, Bell E, Sadka A, Mullet JE. Arabidopsis thaliana Atvsp is homologous to soybean $V s p A$ and $V s p B$, genes encoding vegetative storage protein acid-phosphatases, and is regulated similarly by methyl jasmonate, wounding, sugars, light and phosphate. Plant Mol Biol 1995; 27:933-942.

41 Bell E, Creelman RA, Mullet JE. A chloroplast lipoxygenase is required for wound-induced jasmonic acid accumulation in Arabidopsis. Proc Natl Acad Sci USA 1995; 92:8675-8679.

42 Rupasinghe S, Schuler MA. Homology modeling of plant P450s. Phytochem Rev 2006; 5:473-505.

$43 \mathrm{Xu} \mathrm{L}$, Liu F, Lechner E, et al. The SCF (COI1) ubiquitin- 
ligase complexes are required for jasmonate response in Arabidopsis. Plant Cell 2002; 14:1919-1935.

44 Nelson DR, Schuler MA, Paquette SM, Werck-Reichhart D, Bak S. Comparative genomics of rice and Arabidopsis. Analysis of 727 cytochrome P450 genes and pseudogenes from a monocot and a dicot. Plant Physiol 2004; 135:756-772.

45 Frank MR, Deyneka JM, Schuler MA. Cloning of woundinduced cytochrome P450 monooxygenases expressed in pea. Plant Physiol 1996; 110:1035-1046.

46 Schopfer CR, Ebel J. Identification of elicitor-induced cytochrome P450s of soybean (Glycine max L.) using differential display of mRNA. Mol Gen Genet 1998; 258:315-322.

47 Ralston L, Kwon ST, Schoenbeck M, et al. Cloning, heterologous expression, and functional characterization of 5-epiaristolochene-1,3-dihydroxylase from tobacco (Nicotiana tabacum). Arch Biochem Biophys 2001; 393:222-235.

48 Siminszky B, Gavilano L, Bowen SW, Dewey RE. Conversion of nicotine to nornicotine in Nicotiana tabacum is mediated by CYP82E4, a cytochrome P450 monooxygenase. Proc Natl Acad Sci USA 2005; 102:14919-14924.

49 Radwanski ER, Last RL. Tryptophan biosynthesis and metabolism: biochemical and molecular genetics. Plant Cell 1995; 7:921-934.

50 Zhao Y, Hull AK, Gupta NR, et al. Trp-dependent auxin biosynthesis in Arabidopsis: involvement of cytochrome P450s CYP79B2 and CYP79B3. Genes Dev 2002; 16:3100-3112.

51 Hansen BG, Halkier BA. New insight into the biosynthesis and regulation of indole compounds in Arabidopsis thaliana. Planta 2005; 221:603-606.

52 Sugawara S, Hishiyama S, Jikumaru Y, et al. Biochemical analyses of indole-3-acetaldoxime-dependent auxin biosynthesis in Arabidopsis. Proc Natl Acad Sci USA 2009; 106:5430-5435.

53 Celenza JL, Quiel JA, Smolen GA, et al. The Arabidopsis ATR1 Myb transcription factor controls indolic glucosinolate homeostasis. Plant Physiol 2005; 137:253-262.

54 Barlier I, Kowalczyk M, Marchant A, et al. The SUR2 gene of Arabidopsis thaliana encodes the cytochrome P450 CYP83B1, a modulator of auxin homeostasis. Proc Natl Acad Sci USA 2000; 97:14819-14824.

55 Bak S, Tax FE, Feldmann KA, Galbraith DW, Feyereisen R. CYP83B1, a cytochrome P450 at the metabolic branch point in auxin and indole glucosinolate biosynthesis in Arabidopsis thaliana. Plant Cell 2001; 12:101-111.

56 Mikkelsen MD, Naur P, Halkier BA. Arabidopsis mutants in the $C-S$ lyase of glucosinolate biosynthesis establish a critical role for indole-3-acetaldoxime in auxin homeostasis. Plant $J$ 2004; 37:770-777.

57 Zhou N, Tootle TL, Glazebrook J. Arabidopsis PAD3, a gene required for camalexin biosynthesis, encodes a putative cytochrome P450 monooxygenase. Plant Cell 1999; 11:24192428.

$58 \mathrm{Xu}$ L, Liu F, Wang Z, et al. An Arabidopsis mutant cexl exhibits constant accumulation of jasmonate-regulated AtVSP, Thi2.1 and PDF1.2. FEBS Lett 2001; 494:161-164.

59 Stintzi A, Weber H, Reymond P, Browse J, Farmer EE. Plant defense in the absence of jasmonic acid: the role of cyclopentenones. Proc Natl Acad Sci USA 2001; 98:12837-12842.

60 Devoto A, Ellis C, Magusin A, et al. Expression profiling re- veals COI1 to be a key regulator of genes involved in woundand methyl JA-induced secondary metabolism, defence, and hormone interactions. Plant Mol Biol 2005; 58:497-513.

61 Taki N, Sasaki-Sekimoto Y, Obayashi T, et al. 12-Oxo-phytodienoic acid triggers expression of a distinct set of genes and plays a role in wound-induced gene expression in Arabidopsis. Plant Physiol 2005; 139:1268-1283.

62 Grant MR, Jones JDG. Hormone (dis)harmony moulds plant health and disease. Science 2009; 324:750-752.

63 Mewis I, Appel HM, Hom A, Raina R, Schultz JC. Major signaling pathways modulate Arabidopsis glucosinolate accumulation and response to both phloem-feeding and chewing insects. Plant Physiol 2005; 138:1149-1162.

64 Ehlting J, Sauveplane V, Olry A, Ginglinger JF, Provart NJ, Werck-Reichhart D. An extensive (co-)expression analysis tool for the cytochrome P450 superfamily in Arabidopsis thaliana. BMC Plant Biol 2008; 8:47.

65 Boerjan W, Cervera MT, Delarue M, et al. Superroot, a recessive mutation in Arabidopsis, confers auxin overproduction. Plant Cell 1995; 7:1405-1419.

66 Grubb CD, Zipp BJ, Ludwig-Muller J, Masuno MN, Molinski TF, Abel S. Arabidopsis glucosyltransferase UGT74B1 functions in glucosinolate biosynthesis and auxin homeostasis. Plant J 2004; 40:893-908.

67 Yanofsky C, Horn V. Role of regulatory features of the trp operon of Escherichia coli in mediating a response to a nutritional shift. J Bacteriol 1994; 176:6245-6254.

68 Kreps JA, Ponappa T, Dong W, Town CD. Molecular basis of alpha-methyltryptophan resistance in amt-1, a mutant of Arabidopsis thaliana with altered tryptophan metabolism. Plant Physiol 1996; 110:1159-1165.

69 Li J, Last RL. The Arabidopsis thaliana trp5 mutant has a feedback-resistant anthranilate synthase and elevated soluble tryptophan. Plant Physiol 1996; 110:51-59.

70 Sun JQ, Xu YX, Ye SQ, et al. Arabidopsis ASA1 is important for jasmonate-mediated regulation of auxin biosynthesis and transport during lateral root formation. Plant Cell 2009; 21:1495-1511.

71 Thomma BPHJ, Eggermont K, Penninckx IAMA, et al. Separate jasmonate-dependent and salicylate-dependent defenseresponse pathways in Arabidopsis are essential for resistance to distinct microbial pathogens. Proc Natl Acad Sci USA 1998; 95:15107-15111.

72 Liu YG, Mitsukawa N, Oosumi T, Whittier RF. Efficient isolation and mapping of Arabidopsis thaliana T-DNA insert junctions by thermal asymmetric interlaced PCR. Plant $J$ 1995; 8:457-463.

73 Shaw CH. Introduction of cloning plasmids into Agrobacterium tumefaciens. Methods Mol Biol 1995; 49:33-37.

74 Jefferson RA, Kavanagh TA, Bevan MW. GUS fusions: betaglucuronidase as a sensitive and versatile gene fusion marker in higher plants. EMBO J 1987; 6:3901-3907.

75 Koch E, Slusarenko AJ. Arabidopsis is susceptible to infection by a downy mildew fungus. Plant Cell 1990; 2:437-445.

76 Grubb CD, Gross HB, Chen DL, Abel S. Identification of Arabidopsis mutants with altered glucosinolate profiles based on isothiocyanate bioactivity. Plant Sci 2002; 162:143-152.

(Supplementary information is linked to the online version of the paper on the Cell Research website.) 